\title{
LAS INNOVACIONES TECNOLÓGICAS EN LA ARQUITECTURA
}

\section{(THE TECHNOLOGICALS INNOVATIONS IN THE ARCHITECTURE)}

Felipe J. Pérez-Somarriba, Arquitecto

Profesor Asociado de la E.T.S. de Arquitectura de Madrid. Coordinador del Área Externa de la Fundación Cultural COAM

ESPAÑA

Fecha de recepción: $25-X-96$

\section{RESUMEN}

La arquitectura es arte y ciencia. Los principios cientificos de la arquitectura están relacionados con la construcción de los edificios. La evolución en las tecnologías constructivas a lo largo de la historia, demuestra el esfuerzo constante del hombre por crear y construir nuevos espacios. Esta evolución se expone cronológicamente a través de edificios construidos en diferentes épocas. Finalmente, se hace una reflexión sobre la situación actual y futura de las innovaciones tecnológicas en la arquitectura y sus posibilidades de aplicación.

\section{SUMMARY}

The architecture is art and science. The scientifics introductions of the architecture are related with the buildings constructions. The evolution in the technologicals innovations along the human history, show the constant effort of the man for the creation and the construction of news spaces. This evolution show cronologically through of buildings of differents periods. Finally, on think about the present and the future of the technologicals innovations in the architecture and the possibilities of application.

\section{La arquitectura como ciencia}

El Diccionario de la Real Academia Española (1) define la arquitectura como "el arte de proyectar y construir edificios". Véase que no emplea la palabra ciencia. Tampoco aparece en la palabra construcción, definida como "arte de construir" ni en el término construir que es "fabricar, erigir, edificar, y hacer de nueva planta una cosa". Por el contrario, define la ingeniería como "el conjunto de conocimientos y de técnicas, que permiten aplicar el saber científico a la utilización de la materia y de las fuentes de energía, mediante invenciones o construcciones útiles para el hombre".

E1 Diccionario de las Nobles Artes, de Rejón de Silva (2), editado a finales del s. XVIII, es más claro que la Real
Academia al definir la arquitectura como "el arte que enseña a trazar y construir un edificio con firmeza, solidez y hermosura, según el destino que ha de tener". Estas tres características sin duda hacen referencia a las tres condiciones que debe tener todo edificio para Vitruvio, y que no eran exactamente ésas, sino solidez, comodidad y belleza, las cuales se consiguen mediante la ordenación y disposición de las partes que lo componen, en la debida proporción, decoro y economía.

Y es precisamente Vitruvio, en sus Diez Libros de Arquitectura (3) del s. I a.d.C. quien define la arquitectura como "una ciencia que debe ir acompañada de mucha variedad de estudios y conocimientos, por medio de los cuales juzga de todas las obras de las demás artes que tienen relación con ella". Es significativo que sea un tratadista 
romano el que hable del carácter científico de la arquitectura y que este carácter se haya "perdido", al menos explícitamente, en definiciones posteriores.

Si el equilibrio, o la búsqueda del mismo entre las tres condiciones vitruvianas, ha sido el denominador común de la arquitectura durante siglos, a partir del Renacimiento, empezará a establecerse en los tratados de Arquitectura una cierta dicotomía entre la técnica y la belleza, que llega hasta nuestros días

Sirva esta introducción para decir algo que de por si resulta obvio: la arquitectura es arte y ciencia, aspecto éste vinculado a la técnica de la construcción de edificios, tanto a nivel de proyecto como de procedimientos constructivos en obra. Análogamente, también podría decirse que algunos ejemplos de ingeniería constituyen verdaderas obras de arte.

Las reglas de la construcción son las que permiten conformar los edificios, a partir de unos materiales y elementos constructivos que deben relacionarse adecuadamente entre sí, para cumplir unos condicionantes y satisfacer las necesidades del hombre. Estas reglas constructivas son las que pertenecen al campo científico, y como tales, sujetas al desarrollo y evolución de la ciencia. Prueba de ello, es que las innovaciones tecnológicas se han ido produciendo a lo largo de la historia, si bien es cierto que en unas épocas más que en otras (4).

\section{La evolución en la tecnología constructiva de los} edificios

Cualquier construcción está formada por un conjunto de partes o elementos unidos entre sí. Esta definición, aparentemente simple, llevaimplícita una gran complejidad. La idea materializada de edificio requiere la ordenación de un espacio, lo que supone la necesidad de una estructura y/o envolvente, y, además, el cumplimiento de unas exigencias, diferentes en cada época y en cada lugar.

Hasta bien entrado el s. XIX, la construcción de los edificios tiene un denominador común: las estructuras de fábrica formadas por piezas que cumplen las leyes de traba entre sí y las de cohesión entre piezas y aglomerante. Las grandes masas de materiales que trabajan fundamentalmente a compresión: barro, piedra, cerámica, son los elementos que definen, no sólo la estructura y los cerramientos del edificio, sino la configuración del espacio interior. El grado de satisfacción de las exigencias constructivas, estructurales y de habitabilidad-confort de ese espacio, se confía, sobre todo, al espesor de los materiales. El Panteón de Roma, construido en el s. I a.de C. y ejemplo paradigmático de la arquitectura romana tiene una cúpula semiesférica rebajada de casi 45 metros de diámetro, cúpula cuyo espesor en el ojo superior central es de $1,40 \mathrm{~m}$ y que se apoya en un anillo perimetral de 7,30 $\mathrm{m}$ de espesor y $4,50 \mathrm{~m}$ de profundidad (Figura 1 )

En el estudio de las estructuras de fábrica, hay que significar las innovaciones estructurales de la arquitectura gótica, en especial durante los ss. XII y XIII (5). Las estructuras de bóvedas nervadas cuyo empuje es contrarrestado por arbotantes, que a su vez transmiten las cargas a otros elementos, se basaron en métodos empíricos, pero consiguieron alcanzar unos notables equilibrios de fuerzas, y además, con bajos niveles tensionales de las fábricas (Figura 2)

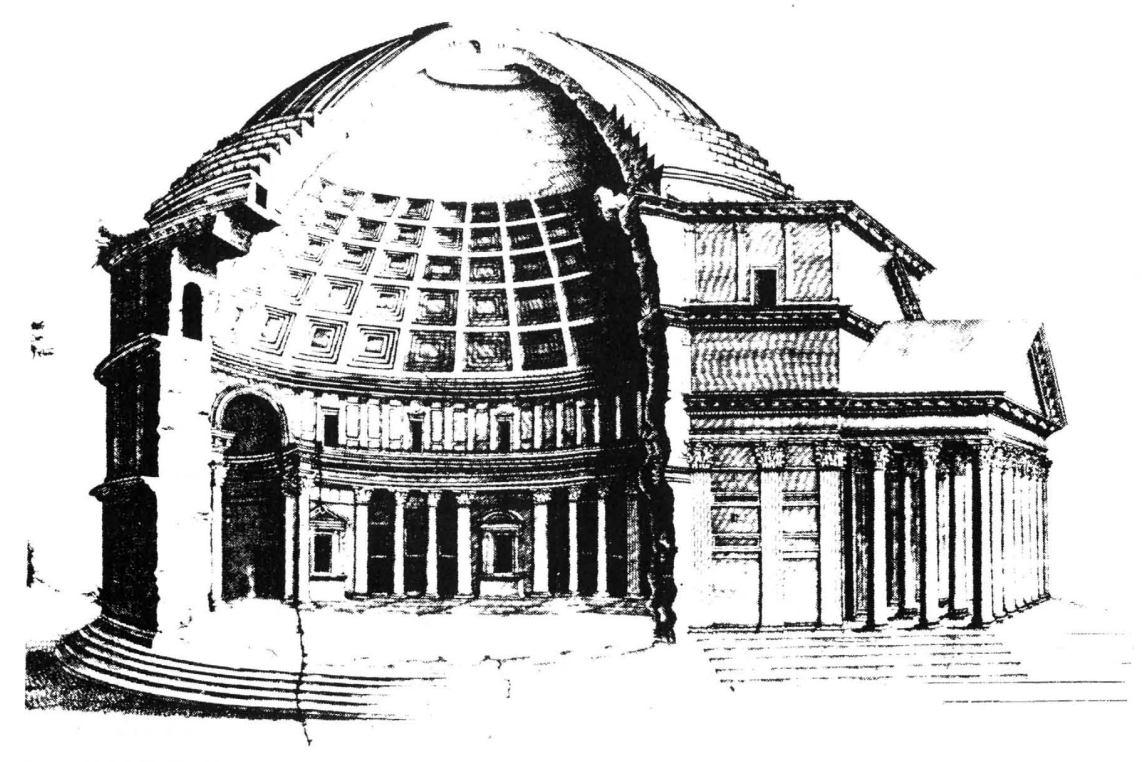

Fig. I.- Panteón de Roma (s. I a. de ('.). Perspectiva seccionada. 


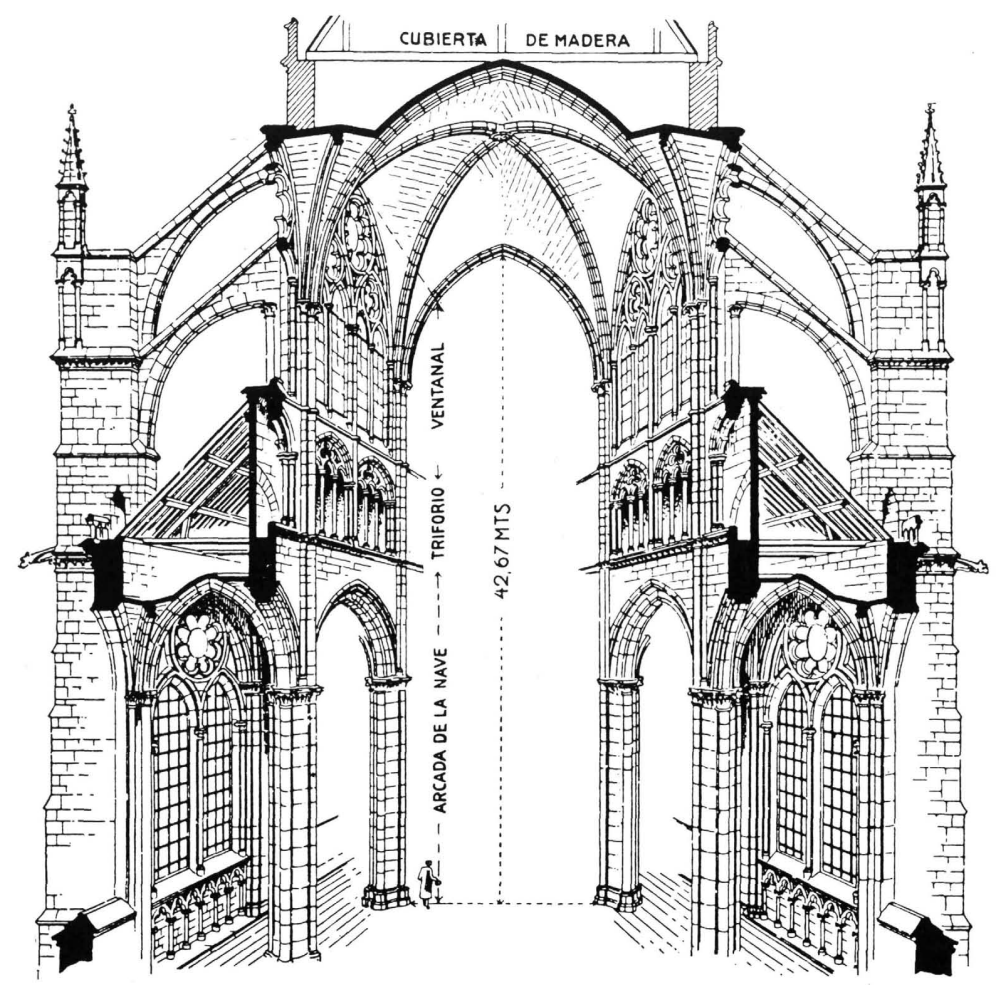

Fig. 2.- Sección de la Catedral gótica de Amiens (s. XIII), según B. Fletcher.

La aparición en el s. XIX del hierro fundido, el acero y el hormigón armado como elementos estructurales lineales, supuso un cambio radical en la arquitectura, que ya conocía desde el s. XVII los estudios de la mecánica elástica de Hooke. La posibilidad de separar los conceptos de estructura y cerramiento en los edificios, significaba tener una libertad de composición en planta y alzado, que antes no permitían las gruesas estructuras de fábrica, al tiempo que se conseguía un mayor aprovechamiento del espacio útil. En el s. XX, el impulso del movimiento moderno a las estructuras porticadas y, por tanto, a la diferenciación entre estructura y cerramiento, fue total, y las estructuras de fábrica cayeron en desuso, sin analizar las bondades que en determinadas circunstancias presentan.

Con el precedente de la Orangerie de Viena de 1737 , invernadero de madera con fachada modular y desmontable, el Chrystal Palace, construido en Londres con motivo de la $1^{\text {a }}$ Exposición Universal de 1851 por J. Paxton, constituye una obligada referencia. Su arquitectura de hierro fundido y madera como estructura, y vidrio como cerramiento, supuso un nuevo planteamiento estético, funcional y constructivo. Fue la apuesta por la tecnología de la prefabricación y del montaje (Figura 3). El edificio, con $70.000 \mathrm{~m}^{2}$ de superficie, se construyó en menos de un año, en una época en que la renovación industrial ya era un hecho. Las leyes de traba y de la cohesión de las fábricas, dieron paso a las leyes de fijación de las múltiples piezas

(c) Consejo Superior de Investigaciones Científicas Licencia Creative Commons 3.0 España (by-nc) que forman los elementos. La rapidez en la construcción fue otra consecuencia del cambio, al reducir en las obras los materiales no conformados que requieren agua, como los morteros o los yesos y, por consiguiente, reducir el tiempo de secado en obra de esos materiales. Sin embargo, aparecieron otros problemas como las uniones y compatibilidades de piezas y el control de las deformaciones producidas por movimientos mecánicos e higrotérmicos (6).

Los avances en la tecnología de los materiales y de las estructuras permitieron otra nueva posibilidad: la construcción de edificios en altura con piezas de razonables esbelteces. Para ello, fue fundamental que E. Otis inventaraen 1854 el "ascensor de seguridad". En 1875 se construyó el edificio de la Western Union en Broadway, de diez plantas, todavía con estructura de pilares interiores y muros exteriores de carga de 2,75 m de espesor. En 1890 Eiffel ya había construido su torre, en 1915 se levantó el Woolworth Building de sesenta plantas y en años sucesivos las alturas han seguido aumentando (Figura 4).

Al igual que la construcción en altura, el crecimiento de las distancias salvadas por elementos estructurales lineales ha sido objeto de una constante investigación (7). Ante la limitación de los cantos de las piezas en relación con las distancias libres de apoyo, los estudios científicos avanzaron en otro campo: las estructuras estéreas formadas por barras 

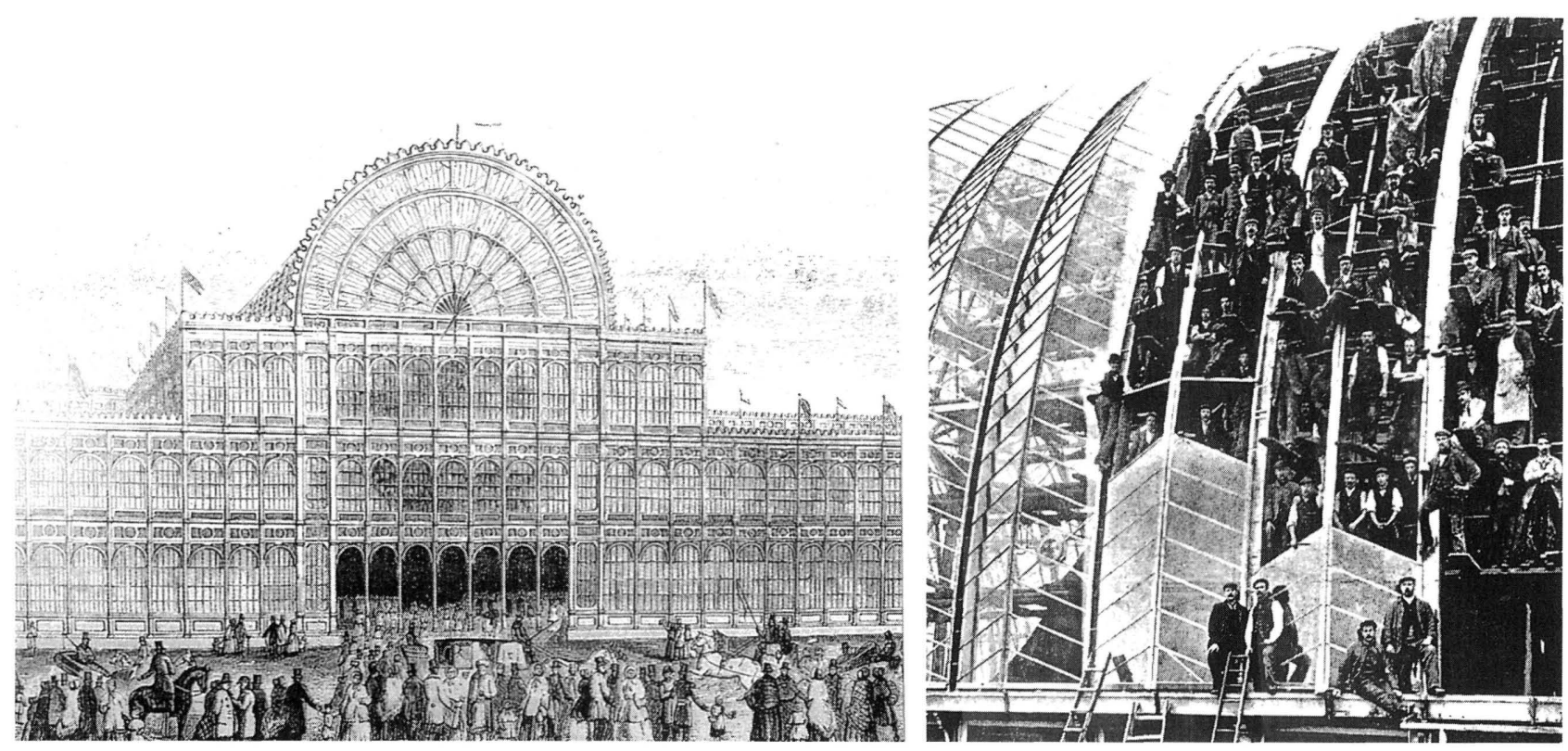

Fig. 3.- ('hrystal Palace de.J. Paxton (1851). Fachada principal y proceso de montaje de los vidrios de la bóveda.

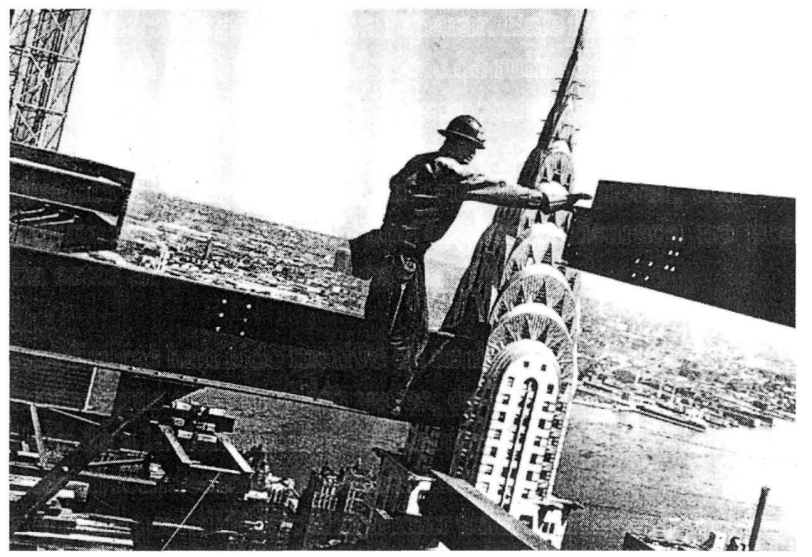

Fig. t.- Construcción de rascacielos frente al Chrysler Building en Nueva York (1960)

que concurren en nudos. Fue K. Wachsmann, quien para la construcción de hangares americanos en 1945, construyó una estérea reticulada de dos capas, formadas por vigas en celosía y barras de arriostramiento en los planos de los cordones superior e inferior, con distancias entre pilares de hasta $49 \mathrm{~m}$. (Figura 5)

En el desarrollo de las estructuras espaciales de grandes luces es R. B. Fuller el que dio un nuevo paso con sus cúpulas geodésicas de icosaedros sin apoyos intermedios. La forma cupular proporciona el máximo volumen a la mínima superficie. La cúpula geodésica, de $70 \mathrm{~m}$ de diámetro, construida para el Pabellón de EE.UU. en la Exposición Universal de Montreal de 1967 es un claro ejemplo (Figura 6). Igualmente, las estéreas desplegables de E. Pérez Piñero, introducen la variabilidad del esta- do estructural, con nudos articulados que permiten la movilidad de la estructura, y, por tanto, del espacio.

El nudo estructural en el que se unen varias barras y que es receptor de los esfuerzos y a la vez transmisor de los mismos, adquiere casi tanta importancia como la necesidad de aligerar no sólo el peso de la estructura sino de todo el edificio (Figura 7). A ello contribuirán en gran medida los nuevos materiales ligeros que se van utilizando, como las aleaciones, los plásticos, los textiles o los materiales compuestos (8). Un caso diferente de estructura-cerramiento singular con un material "pesado" como el hormigón armado, que, sin embargo, tiene la cualidad de ser formáceo, son las construcciones de láminas y superficies regladas, en las que la optimización estructural y la geometría se unen para conseguir grandes espacios con cáscaras homogéneas de pocos centímetros de espesor, como los edificios de $\mathrm{F}$. Candela, E. Torroja o P.L. Nervi (Figura 8). En estos edificios, la principal dificultad estriba en los refuerzos de las armaduras, en la transmisión de esfuerzos a los bordes y en el encofrado del hormigón. La técnica del pretensado también ha conseguido ejemplos de estructuras de grandes luces.

Fue precisamente el estudio de la optimización de las estructuras traccionadas, el que llevó a F. Otto a trabajar con estructuras de cables tensados que sustentan superficiesmembranas. Las instalaciones olímpicas de Munich construidas en 1972, cubren un espacio de $75.000 \mathrm{~m}^{2}$ con una serie de mástiles anclados al suelo, de los que cuelgan los cables y cordones que sostienen la cubierta formada por placas de metacrilato flexible de $4 \mathrm{~mm}$ de espesor. La compatibilidad de movimientos de la estructura se resuelve 


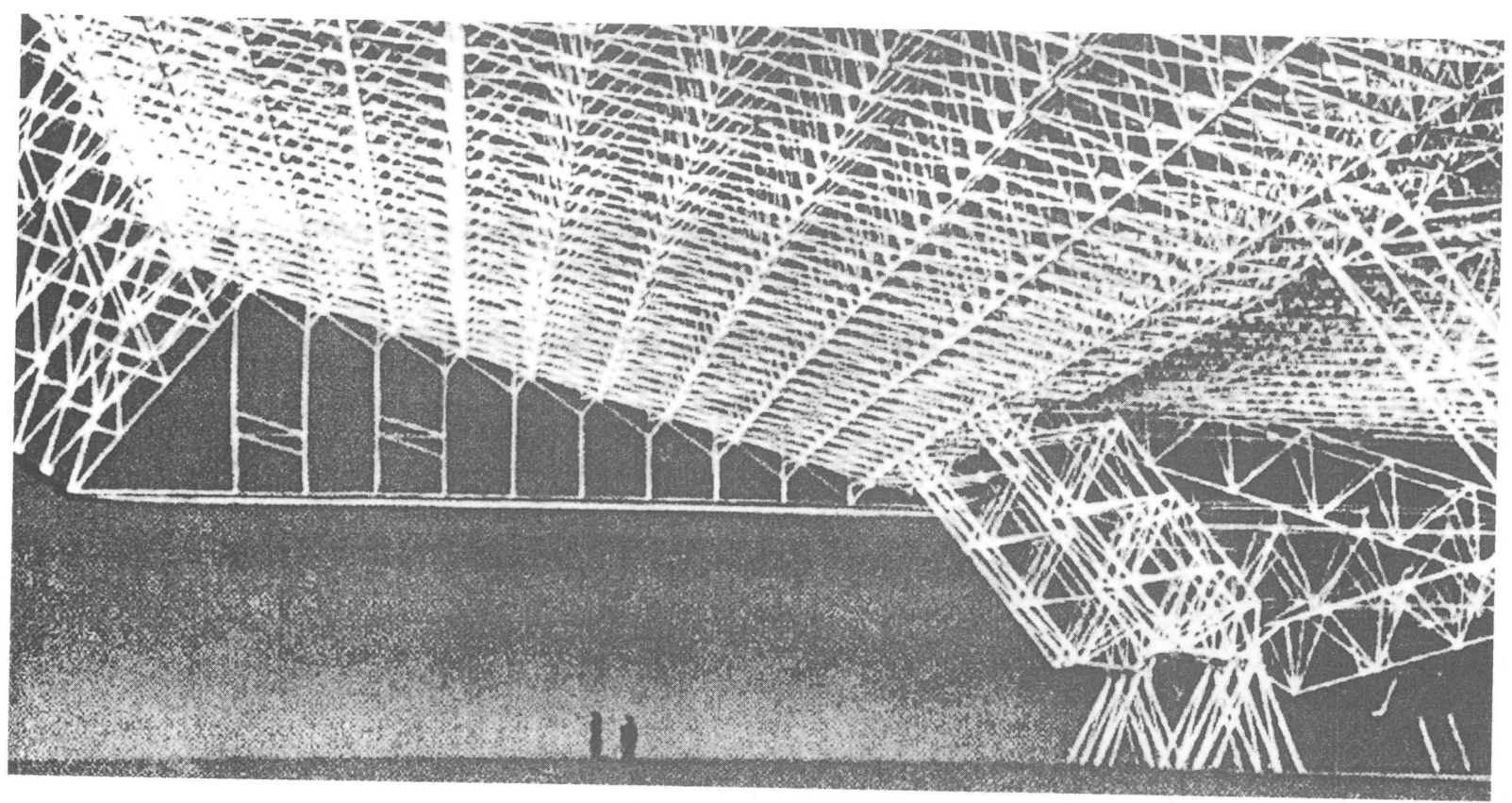

Fig. 5.- Hangares de K. Wachsmann con estructuras estéreas (I945).

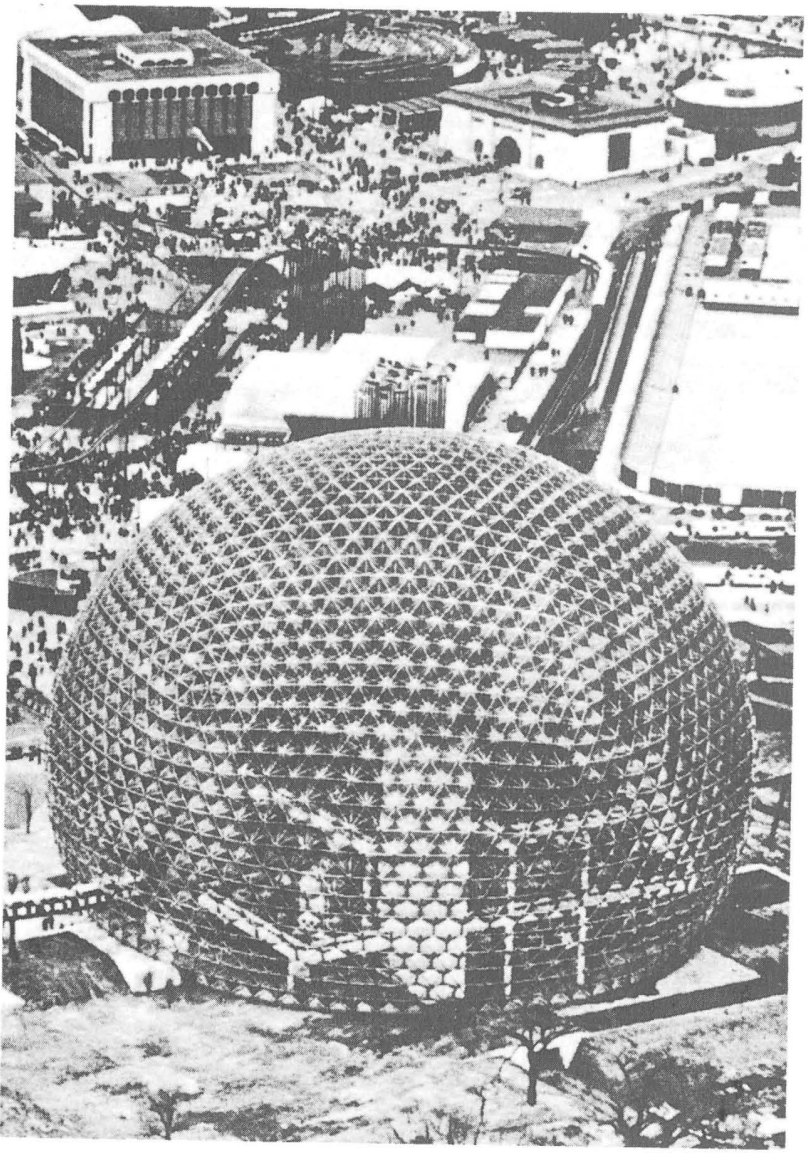

Fig. 6.- Cúpula geodésica de R. B. Fuller para la Expo 67 de Montreal (1967).

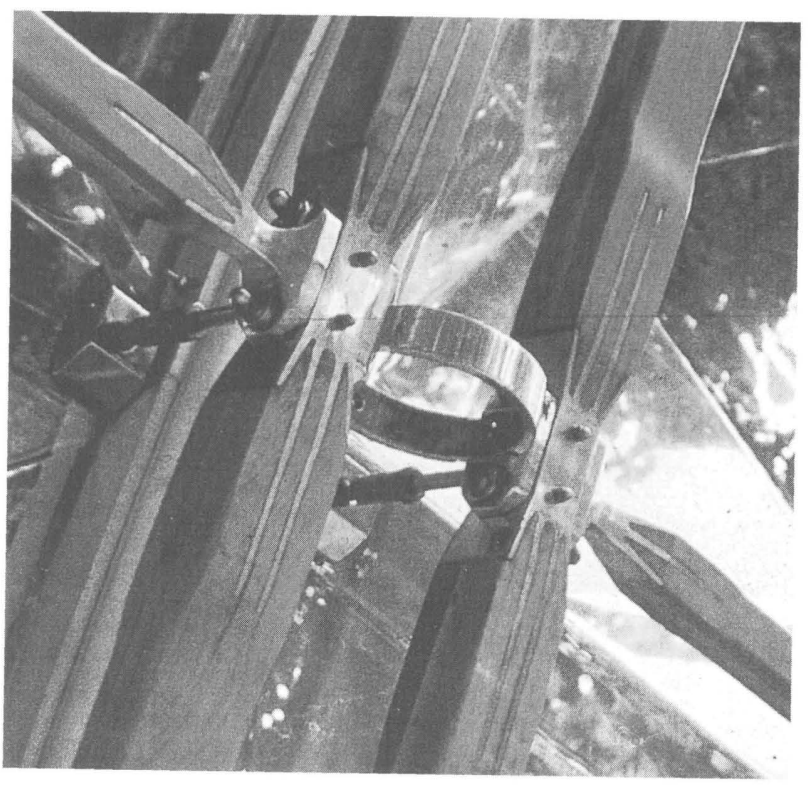

Fig. 7.- Nudo estructural de R. Piano y ()ve Arup-Partners para al Pabellón itinerante de la IBM (1982-86).

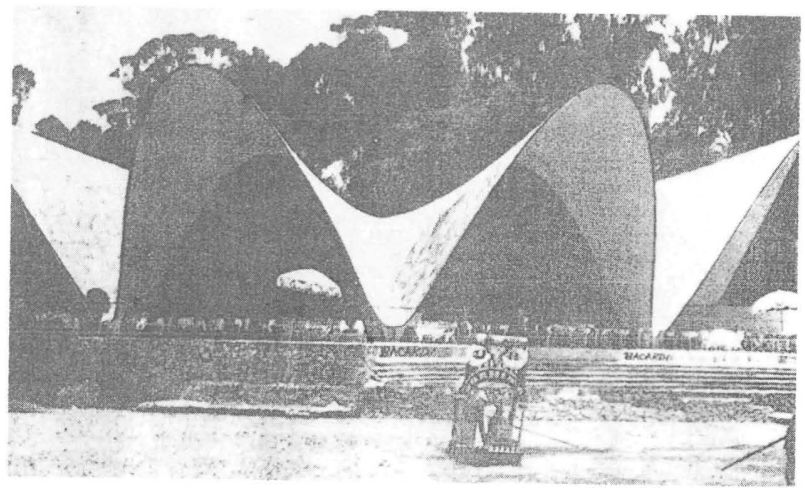

Fig. 8. - Restaurante los Manantiales en Xochimilco, Méjico, de F Candela. Paraboloides hiperbólicos. 
con juntas de neopreno entre las placas y en las fijaciones, juntas que también garantizan la estanquidad (Figura 9).

El estado de equilibrio tensional de la membrana entre las presiones interior y exterior es el principio de las estructuras neumáticas (9), con precedentes en globos aerostáticos y zepelines. De todas las construcciones de este tipo, destaca sin lugar a dudas el proyecto no construido de Ciudad Bioclimática en el Ártico, que en 1971 realizaron, entre otros, F. Otto y E. Bubner (10). Se trata de una cáscara estabilizada neumáticamente con regulación de clima, que tiene un diámetro de $2.000 \mathrm{~m}$ y una altura de $240 \mathrm{~m}$, para albergar de 15.000 a 45.000 habitantes. La membrana transparente está sostenida por una malla de cables entrecruzados de poliéster de $27 \mathrm{~cm}$ de diámetro, de tal forma que se admiten deformaciones volumétricas por cambios de volumen de hasta un 300\% (Figura 10). Desde la cúpula del Panteón a ésta, sólo han transcurrido dos mil años y casi dos mil metros de diámetro.

Lo expuesto anteriormente se refiere a la evolución en la tecnología constructiva de los edificios, desde el punto de
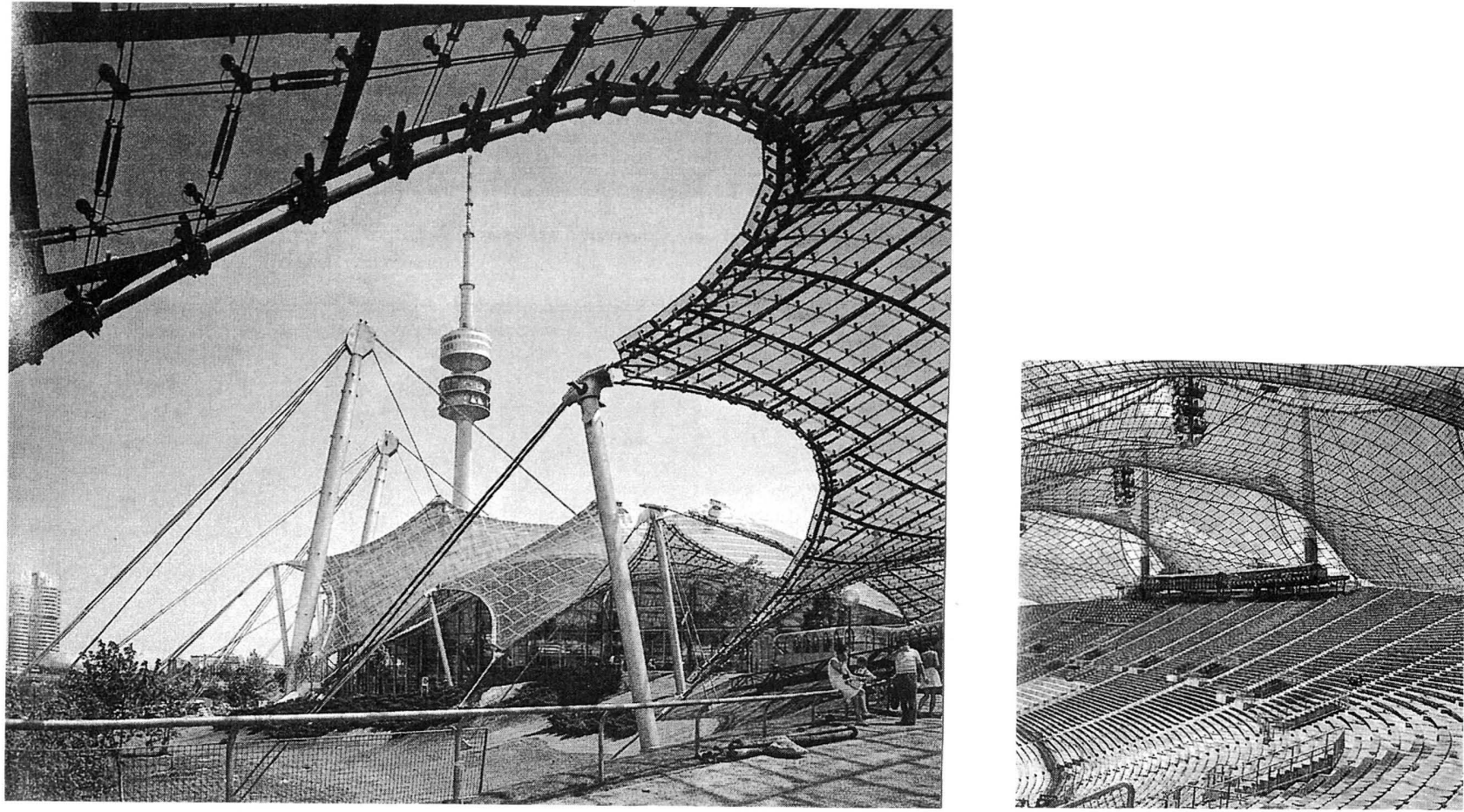

Fig. 9.- ('ubierta de F. Otto para las instalaciones olimpicas de Munich (1972).

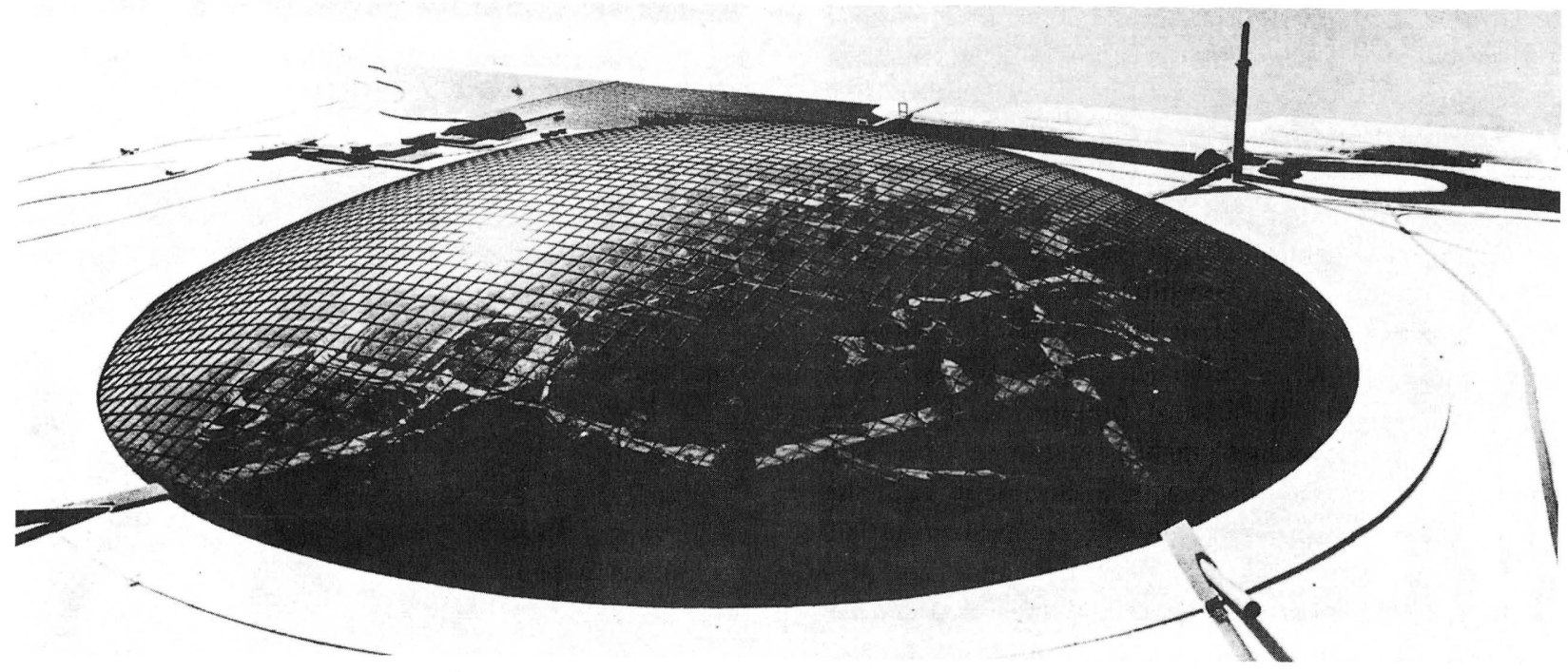

Figy. 10.- ('upula néumática para ('iudad en el Artico, de F. (Oto y E. Bubner, con $2.000 \mathrm{~m}$ de diámetro (19-1). 
vista de la estructura y/o envolvente, siempre en relación con la concepción del espacio interior. En cualquier caso, no se ha entrado en valoraciones formales o funcionales de las soluciones, ni tan siquiera del resultado final de la arquitectura globalmente considerada. Se trata solamente de una muestra del afán de superación del hombre por conseguir sus objetivos, através de lacreación y construcción del espacio.

De modo análogo, podría estudiarse el desarrollo de cada uno de los elementos constructivos constituyentes del edificio: cerramientos exteriores e interiores, cubiertas, estructuras, instalaciones o acabados (11).

\section{Las innovaciones tecnológicas en el presente y en el futuro}

A pesar de la evolución de las tecnologías constructivas, casi toda la arquitectura de hoy día, fundamentalmente privada y al menos en España, no participa de ese esfuerzo técnico por la construcción del espacio. Las soluciones más frecuentes de nuestra arquitectura son: estructuras reticulares de pilares, vigas y forjados de hormigón armado; cerramientos cerámicos, los exteriores de dos hojas con cámara intermedia rellena de aislamiento térmico y los interiores de una hoja; cubiertas multicapas, inclinadas de piezas o planchas sobre tabiques cerámicos o estructuras ligeras, y planas, con membranas impermeabilizantes, más o menos protegidas. Las instalaciones, son probablemente, el campo donde los avances técnicos han sido más notables, sin duda porque las exigencias de confort del hombre son cada vez mayores.

Aunque se han mejorado los procesos de producción, prefabricación y puesta en obra, y por supuesto, los materiales componentes de los elementos constructivos, esta construcción convencional tiene que resolver los mismos problemas de siempre: los espesores, las juntas, y las compatibilidades de materiales y elementos.

El progreso científico aplicado a los materiales y técnicas constructivas permite afirmar que hoy día cualquier solución es técnicamente-científicamente posible y por lo tanto realizable. La cuestión fundamental estriba en determinar a qué precio, y si el coste de la solución es asumible y la hace viable desde el punto de vista económico. No hay que olvidar que ya Vitruvio, otra vez inevitable referencia, consideraba la economía una de las partes de la Arquitectura.

Si se tiene como único objetivo el rendimiento económico, donde el promotor pretende rentabilizar su inversión con el precio de venta del producto inmobiliario, los costes del suelo y de lafinanciación limitan necesariamente el precio de la construcción (12). El hecho de que las obras de arquitectura sean diferentes unas de otras y de que intervengan en ellas múltiples agentes, dificulta el debate de si una determinada solución constructiva "compensa" económicamente para conseguir el equilibrio entre la "firmitas, utilitas y venustas", o, al menos, alguna de las tres condiciones vitruvianas.

El promotor, el arquitecto y el constructor, además del usuario final en determinados casos, deben admitir la relación calidad/precio de las soluciones constructivas, cada uno desde la función que desempeña dentro del proceso edificatorio. Es obvio que en la medida de que las nuevas tecnologías tengan un coste económicamente razonable, serán más viables. El hecho de que los edificios donde se han producido las grandes innovaciones tecnológicas en todas las épocas, sean edificios públicos y no privados, es una evidencia.

Un aspecto importante que debería ser tenido en cuenta en el debate anterior, es el concepto de durabilidad, independientemente del necesario mantenimiento para ello. La arquitectura tradicional nos ha legado magníficos ejemplos de edificios construidos hace cientos de años, y que se han conservado en relativo buen estado. Estos edificios están resueltos básicamente con pocos materiales y elementos. La piedra, la madera, la cerámica, son materiales multifuncionales que dan lugar a una construcción homogénea (Figura 11). La construcción

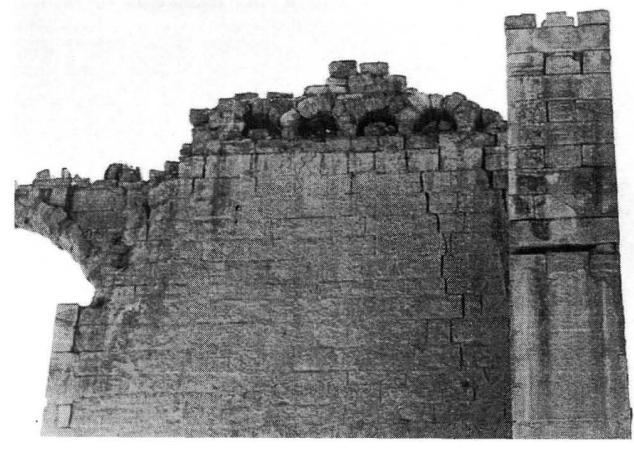

Fig. 11.- Construcción romana (s. I).

heterogénea actual con multitud de materiales y elementos que desempeñan cada uno una única función (Figura 12), tiene problemas de juntas y compatibilidades entre ellos, con una incidencia directa en la durabilidad de la construcción. Desgraciadamente, existen muchos casos de edificios modernos en los que su "avanzada tecnología" es causa de constantes reparaciones, lo que demuestra que las innovaciones tecnológicas deben ser perdurables en el tiempo (Figuras 13 y 14). Y el progreso científico de la construcción sigue su curso. 

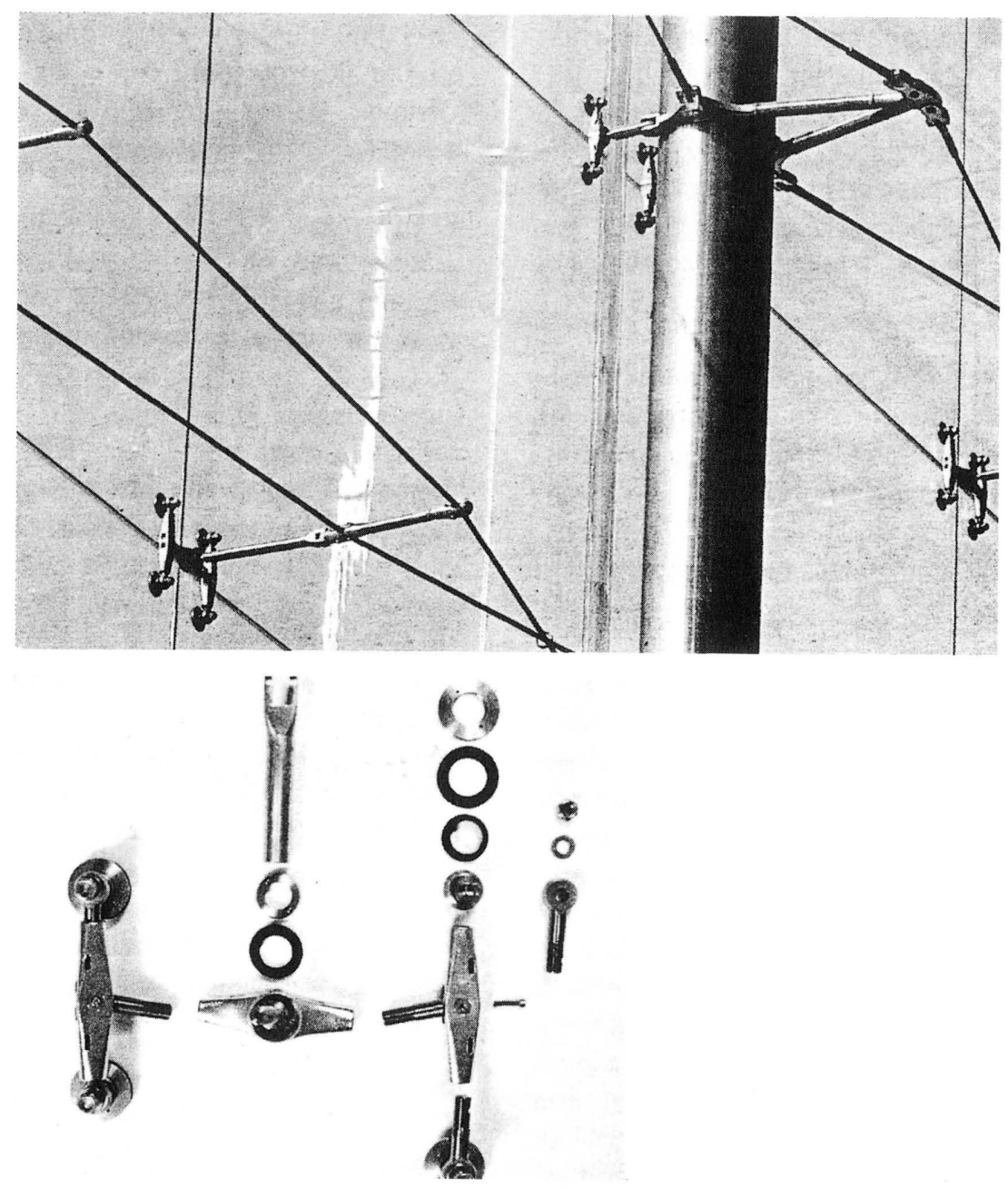

Fig. 12.- Piezas que forman la fijación del vidrio estructural.

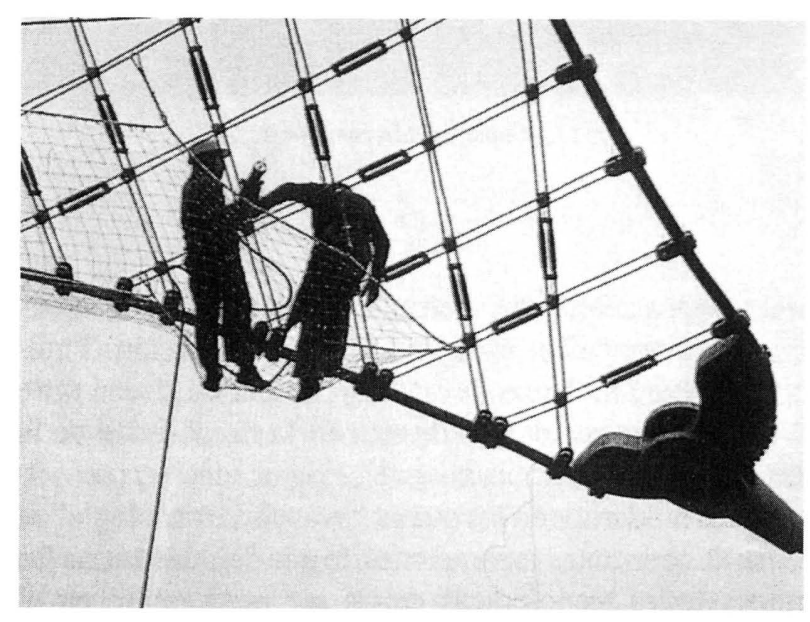

Fig. 13.- Sustitución de las juntas de neopreno en las cubiertas de las instalaciones olimpicas de Munich (1991) (construidas 20 años antes).

\section{NOTAS}

(1) Real Academia Española: "Diccionario dela Lengua Española", Madrid, 1984

(2) REJÓN DE SILVA, DIEGO ANTONIO: "Diccionario de las Nobles Artes para Instrucción de los Aficionados, y uso de los Profesores". Ed. facsímil del COAM, Madrid, 1995, de la Ed. de D. Antonio Espinosa, Segovia, 1788.

(3) VITRUVIO, MARCO: "Los Diez Libros de Arquitectura" Ed.facsímilde AltaFulla, Barcelona, 1993, del mismo libro,traducido del latín y comentado por D. Joseph Ortizy Sanz. Madrid, Imprenta Real, 1787

(4) HAWKES, NIGEL: "El genio del hombre". Ed. Debate, S.A., Círculo de Lectores. Barcelona, 1992.

(5) HEYMAN, JACQUES: "Teoría, historia y restauración de estructuras de fábrica". Ed. a cargo de Santiago Huerta, Instituto Juan de Herrera. Madrid, 1995. 


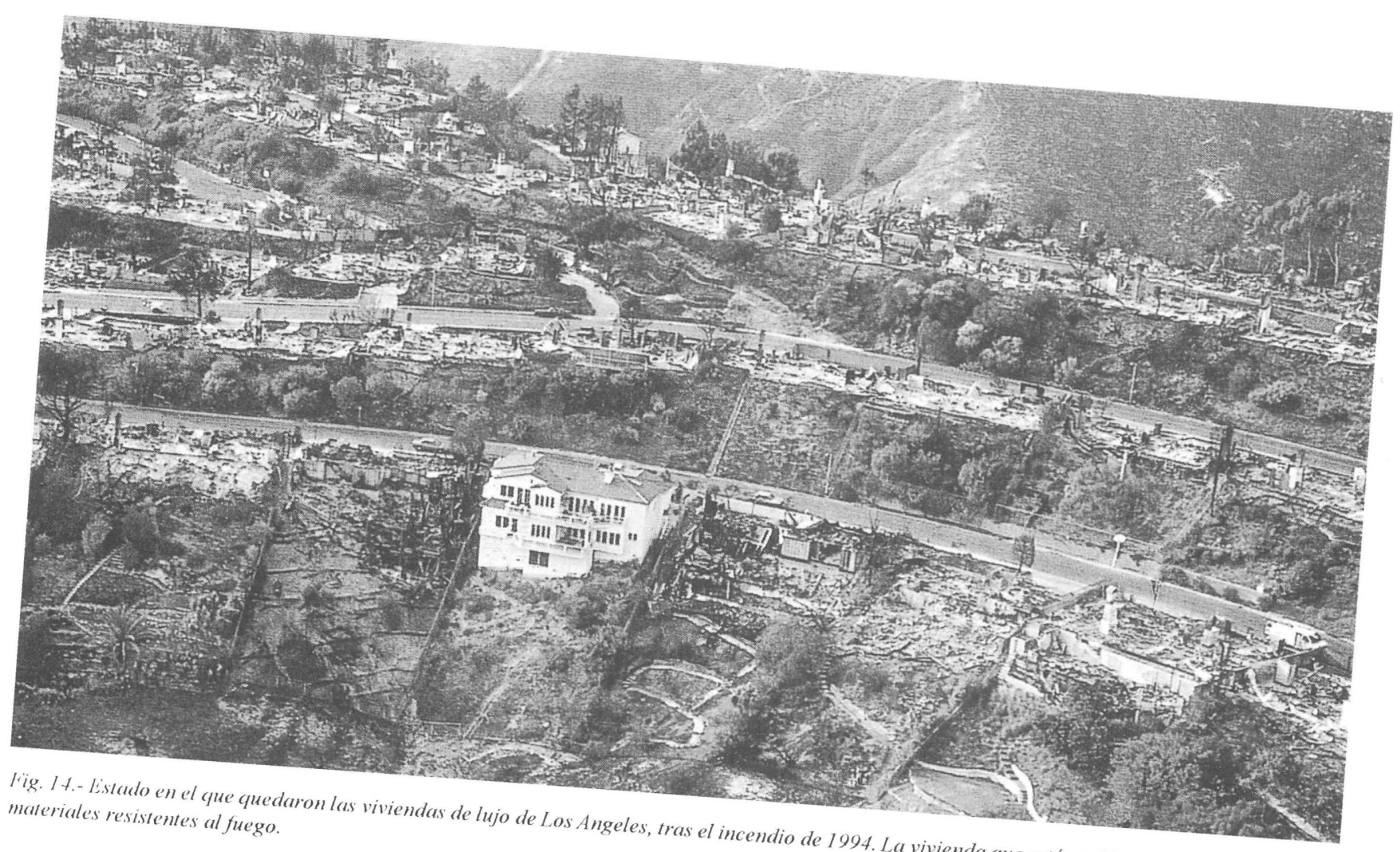

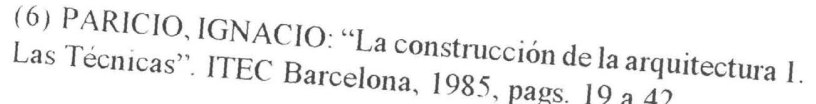

(7) Espiritu Nuevo n ${ }^{\circ}$ 2, 1995: Exposición de la arquitectura de
grandes luces. José Miguel Reyes González pags. 73 a 217 . (8) MIRAVETE, AN

construcción". Ed. A Miravete "Los nuevos materiales en la ragoza, 1994

(9) HERZOG, THOMAS: "Construcciones neumáticas".
Gustavo Gili. Barcelona, 1977.
(10) En el proyecto intervinieron además Kenzo Tange y
URTEC como Consejero de planeamiento URTEC como Consejero de planeamiento urbano, Ove Arup y
Asociados como Consejero estrutural, Farbwo en los Ensayos de Materiales.

(11) PARICIO, IGNACIO: "La 2. Los Elementos". ITEC, Barcelona, 1986.

(12) El coste real del edificio de la Ópe

construido entre 1959 y 1973 , fue Opera de Sidney, de J. Utzon, australianos, frentea los 7 millones de 102 millones de dólares 